\title{
Congenital Anomalies in Neonates Admitted in Neonatal Intensive Care Units, Cairo University
}

\author{
ABDELRAHMAN A. ABDELRAZEK, M.D.*; SAFAA M. ABDELRAHMAN, M.D.*; \\ RANIA M.H. ELKAFASE, M.D.*; IMAN E. ABDEL MEGUID, M.D.** and ZEINAB A. EL-SAYED, M.Sc.* \\ The Department of Pediatrics, Faculty of Medicine, Cairo University* and Pediatrics Department, Ministry of Health**, \\ Cairo, Egypt
}

\begin{abstract}
Background: Congenital anomalies comprise a wide range of abnormalities of body structure or function that are present at birth and are of prenatal origin. Congenital anomalies defined as structural changes that have significant medical, social or cosmetic consequences for the affected individual, and typically require medical intervention. Three to seven percent is the estimated worldwide incidence of congenital anomalies, with 295000 newborns die within 28 days of birth every year worldwide due to congenital anomalies.
\end{abstract}

Aim of Study: This study aims to detect the incidence of congenital anomalies in neonates admitted in Neonatal Intensive Care Units, Cairo University in the year 2014 and the associated risk factors present in their parents.

Patients and Methods: We retrospectively reviewed the records of neonates having congenital anomalies admitted in Neonatal Intensive Care Units, Cairo University Children Hospital over one year from January 2014 to January 2015 Our collected data include full history with pedigree, full clinical examination and investigations.

Results: 1105 neonatal 's records collected from Neonatal intensive care units, Cairo University for one year, four hundred sixty five (42\%) of them having congenital anomalies, with high mortality $(30.5 \%)$ from congenital anomalies, consanguineous marriage represent with $28.8 \%$. Gastrointestinal tract anomalies are the most common congenital anomalies $(48.6 \%)$ followed by cardiovascular system $(24.3 \%)$ respiratory system $(4.3 \%)$ urinary and genetic causes $(1.9 \%)$, mothers have chronic illness represent $(10.3 \%)$ with eight\% took drug during pregnancy.

Conclusion: We found that there is high incidence of congenital anomalies in our Neonatal Intensive Care Units this is mostly related to that we are tertiary referral center and also most of these cases collected from surgical unit and need surgical interference and related to high incidence of consanguineous marriage.

Congenital anomalies can contribute to long-term disability, which may have significant impacts on individuals, families, health-care systems and societies.

Correspondence to: Dr. Abdelrahman A. Abdelrazek, The Department of Pediatrics, Faculty of Medicine, Cairo University, Egypt
The exact causes of congenital anomalies cannot be identified so close follow-up of pregnant women is highly indicated.

Some congenital anomalies can be prevented. For example, vaccination, adequate intake of folic acid or iodine during pregnancy and adequate antenatal care are keys for prevention.

Key Words: Congenital anomalies - (GIT) Gastrointestinal tract - Neonates - Neonatal Intensive Care Unit $(\mathrm{NICU})$.

\section{Introduction}

CONGENITAL anomaly is an abnormal structural or medical condition that presents at birth. A congenital anomaly may be narrowly defined in terms of physical structure as a malformation, an abnormality of physical structure or formusually found at birth or during the first few weeks of life; ordefined more widely to include functional disturbance as a defect, any irreversible condition existing in a child before birth in which there is sufficient deviation in the usual number, size, shape, location or inherent character of any part, organ, cell or cell constituent to warrant its designation as abnormal [1].

The population risk for medically significant birth defects is approximately $3 \%$ of all live-born infants. However, not all birth defects are detected at birth; for example, some forms of kidney disorders, congenital heart disease, and mental retardation are diagnosed later in life. So by adult hood the percent will rise to $7 \%$ of the population [2].

Congenital anomalies accounts for $8 \%$ to $15 \%$ of perinatal deaths and $13 \%$ to $16 \%$ of neonatal deaths [3].

Our study aims to detect the incidence of congenital anomalies among neonates admitted to neonatal units, to identify the types of malforma- 
tions and to determine the different factors associated with occurrence of congenital anomalies e.g gestational age, sex, birth weight, maternal age, consanguinity and how to avoid these risk factors.

\section{Patients and Methods}

We retrospectively reviewed the records of 1105 neonates` files where admitted in Neonatal Intensive Care Units Cairo University during the period from January 2014 to the January 2015 . We found that $465(42.08 \%)$ neonates suffering from congenital anomalies. Our inclusion criteria include all live born neonates admitted in NICU having congenital anomalies.

\section{Our collected data include:}

Family history: Of congenital anomalies, Consanguinity (degree).

Prenatal history: Maternal age at conception, chronic illness of the mother, drug intake during pregnancy (onset, dose, duration).

History of fever, rash, positive TORCH, Rubella vaccine, contact with animals during pregnancy.

Natal history: Gestational birth, the duration of labor, presentation, anomalies of the amniotic liquid, umbilical cord and placenta.

Post natal history: APGAR score / resuscitation of the newborn, its morphological coordinates (weight, length, skull perimeter).

\section{Full clinical examination includes:}

\section{General examination:}

Head, neck, facial features, skin,chestwall, heart and lung and abdomen, Genitalia, anus, extremities.

Neurological examination and reflexes.

- Evaluation of vital signs (heart rate, respiratory rate and blood pressure).

- Assessment of the growth parameters (weight, height, skull circumference), the general habitus of the body and its proportions.

\section{Dysmorphic examination:}

The malformations were classified into major and minor anomalies. Major anomalies are classified by the use of anatomic systems to organize human anomalies according to the International Statistical Classification of Diseases and Related Health Problems, 10th version, for 2007. There are a list of minoranomalies that are to be excluded unless occurring in combination with major anomalies. Minor anomalies can be of importance especially in cases of suspected dysmorphic syndromes and in relation to environmental effects, but there is as yet little standardization in their definition reporting.

\section{Laboratory investigations:}

CBC, CRP, kidney function, liver function, serum electrolytes.

\section{Imaging: Radiological examination.}

Ultrasonography: When indicated, Echocardiography to detect cardiac anomalies.

\section{Statistical analysis:}

Data collected and analyzed by computer program SPSS " ver. 21" Chicago. USA. Data expressed as mean, Standard deviation and number, percentage. Mann-Whitney was used to determine significant for numeric variable. Chi. Square was used to determine significance for categorical variable. ANOVA test using to compare significance between three groups. Person's correlation was used for correlations between two methods of blood loss estimation used in this study.

${ }^{*} p<0.05$ is significant.

\section{Results}

Its cross section study was conducted in the Neonatology Inpatient Department of the children Hospital of Cairo University for all babies delivered during the period from January 2014 to January 2015. From 1105 neonates admission there were 465 (42.08\%) having congenital Anomalies twentyeight percent of patients had consanguineous parents and $53.7 \%$ of them with 1 st degree with high percentage of congenital anomalies with consanguinity with statistically significance difference $(p<0.001)$.

Table (1): Demographic data in study group.

\begin{tabular}{ll}
\hline Item & Descriptive \\
\hline 1- Maternal Age "years" & $27.43 \pm 4.79$ \\
2- Sex of baby: & \\
Female & $158(34.0 \%)$ \\
Male & $307(66.0 \%)$ \\
3- Length "cm" & $47.72 \pm 3.81$ \\
4- Weight & $2.743 \pm 1.79$ \\
5- Gestational age "weeks": & $36.45 \pm 2.61$ \\
Post term & $2(0.4 \%)$ \\
Full term & $336(72.3 \%)$ \\
Preterm & $127(27.3 \%)$
\end{tabular}

Patients with congenital anomalies 48 (10.3\%) oftheir mother have chronic illness, in the form of hypertension, anemia, cardiac diseases, D.M and 
$39(8.4 \%)$ of their mother received drug during Pregnancy mostly antihypertensive medications and Antibiotics The most common congenital anomalies are gastroin testinal tract. Clinical outcome for our patients showed that $142(30.5 \%)$ died and $323(69.5 \%)$ alive with variable degree of disabilities.

Table (2): Description of route of delivery in the study group.

\begin{tabular}{cc}
\hline Item & $\begin{array}{c}\text { Anomalies } \\
\text { " } \mathrm{n}=465 "\end{array}$ \\
\hline Type of delivery: & \\
NVD & $165(35.48 \%)$ \\
C.S & $309(66.45 \%)$ \\
\hline
\end{tabular}

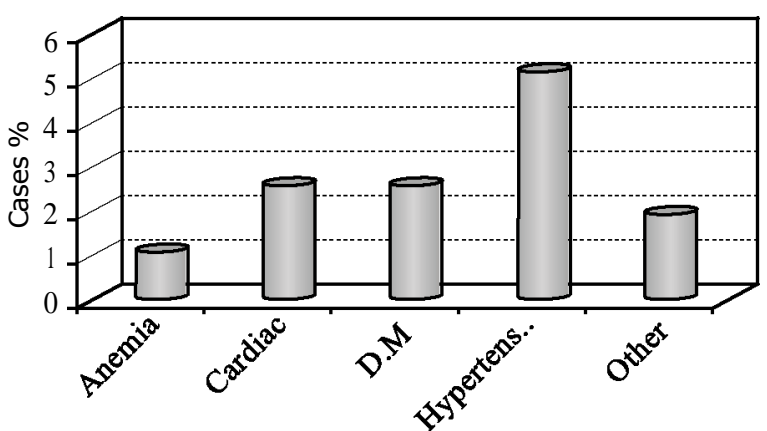

Fig. (1): Shows description of chronic illness of mothers in the study group.

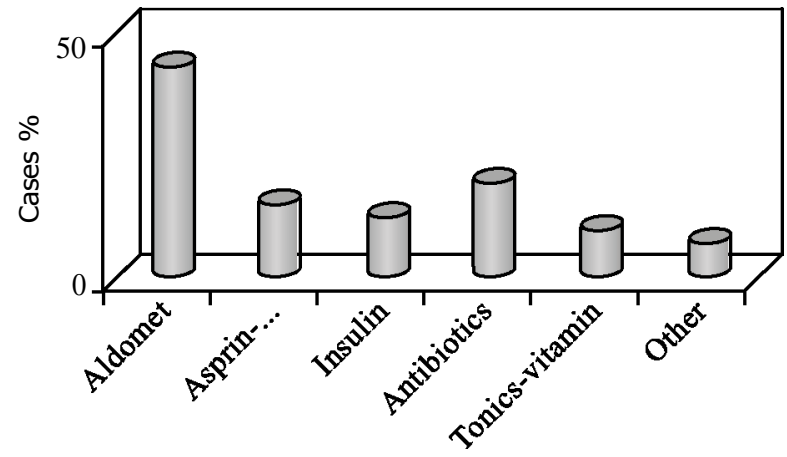

Fig. (2): Type of Drug in the study group.

Table (3): Distribution of congenital anomalies in the study group.

\begin{tabular}{lll}
\hline Item & \multicolumn{2}{c}{$\begin{array}{c}\text { Anomalies } \\
\text { "n=465” }\end{array}$} \\
\hline GIT & 226 & $(48.60 \%)$ \\
CVS & 113 & $(24.30 \%)$ \\
Respiratory & 68 & $(14.62 \%)$ \\
Musculoskeletal & 66 & $(14.19 \%)$ \\
CNS & 20 & $(4.30 \%)$ \\
Chromosomal & 9 & $(1.93 \%)$ \\
Urinary & 9 & $(1.93 \%)$ \\
Other Congenital anomalies & 57 & $(12.25 \%)$ \\
\hline
\end{tabular}

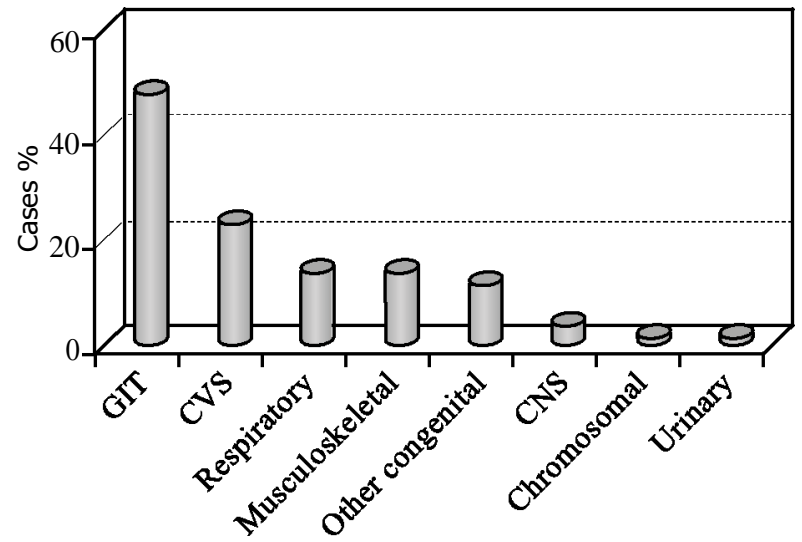

Fig. (3): Distribution of congenital anomalies in the study group.

Table (4): Distribution of GIT anomalies in the study group.

\begin{tabular}{ll}
\hline Item & $\begin{array}{c}\text { Anomalies } \\
\text { "n=226" }\end{array}$ \\
\hline GIT: & $71(31.41 \%)$ \\
Intestinal obstruction & $50(22.12 \%)$ \\
Imperforate anus & $47(20.79 \%)$ \\
TOF & $18(7.96 \%)$ \\
CHPS & $9(3.98 \%)$ \\
Duodenal atresia & $8(3.53 \%)$ \\
Hirshsprung disease & $6(2.65 \%)$ \\
Mesenteric cyst & $3(1.32 \%)$ \\
Oseophgeal atresia & $2(0.88 \%)$ \\
Volvulus & $2(0.88 \%)$ \\
Ileal atresia & $2(0.88 \%)$ \\
Cloacol exstrophy & $2(0.88 \%)$ \\
Cholestasis & $2(0.88 \%)$ \\
Malrotation & $1(0.44 \%)$ \\
Gastroesophgeal reflux & $1(0.44 \%)$ \\
Cloacol obstruction & $1(0.44 \%)$ \\
Duodenal web & $1(0.44 \%)$ \\
Hepato splenomegaly &
\end{tabular}

Table (4) shows distribution of GIT anomalies in the study group with high percentage of intestinal obstruction $71(31.41 \%)$ and $50(22.12 \%)$ of imperforate anus.

Table (5): Shows Mortality from congenital anomalies in the study group.

\begin{tabular}{cc}
\hline Item & $\begin{array}{c}\text { Anomalies } \\
\text { "n=465" }\end{array}$ \\
\hline Mortality: & \\
Died & $142(30.53 \%)$ \\
Live & $323(69.46 \%)$ \\
\hline
\end{tabular}


Table (6): Relation between congenital anomalies and drug intake in the study group.

\begin{tabular}{llll}
\hline Item & \multicolumn{1}{c}{ No } \\
"n=426" & $\begin{array}{c}\text { Yes } \\
\text { "n=39” }\end{array}$ & $p$-value \\
\hline GIT & $200(46.94 \%)$ & $20(51.28 \%)$ & $p<0.02 *$ \\
CVS & $101(23.70 \%)$ & $11(28.20 \%)$ & \\
Other congenital & $57(13.38 \%)$ & $9(23.07 \%)$ & \\
$\quad$ anomalies & & & \\
Respiratory & $62(14.55 \%)$ & $6(15.38 \%)$ & \\
Musculoskeletal & $62(14.55 \%)$ & $4(10.25 \%)$ & \\
Urinary & $7(1.64 \%)$ & $2(5.12 \%)$ & \\
Chromosomal & $8(1.87 \%)$ & $1(2.56 \%)$ & \\
CNS & $20(4.69 \%)$ & - \\
\hline
\end{tabular}

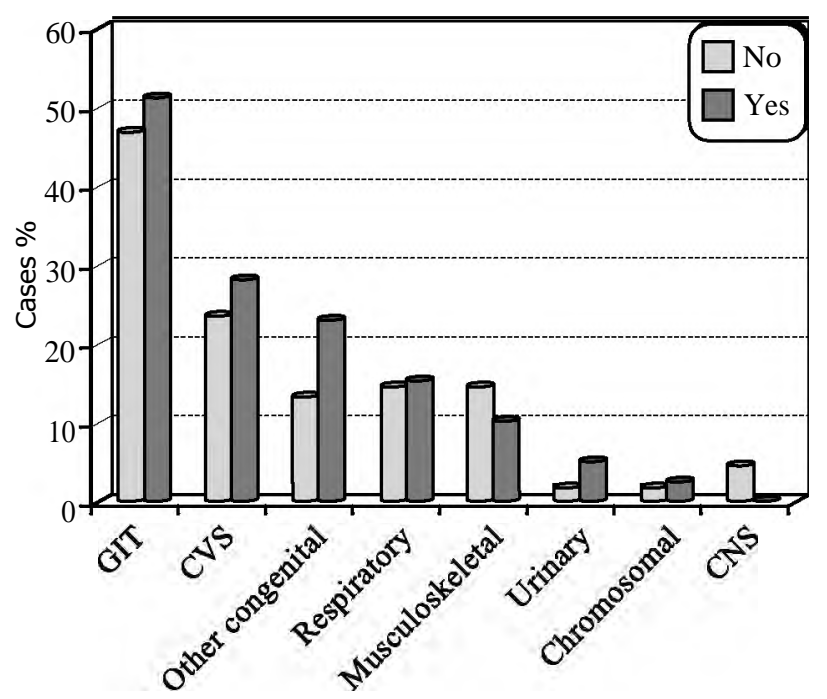

Fig. (4): Relation between congenital anomalies and drug intake.

Table (7): Shows relation between congenital anomalies and consanguinity in the study group with high percentage of congenital anomalies with consanguinity with significance difference $(p<0.001)$.

\begin{tabular}{llll}
\hline Item & \multicolumn{1}{c}{ No } \\
"n=333" & $\begin{array}{c}\text { Yes } \\
\text { "n=132” }\end{array}$ & $p$-value \\
\hline GIT & $153(45.94 \%)$ & $66(50.0 \%)$ & $p<0.001 * *$ \\
CVS & $83(24.92 \%)$ & $33(25.0 \%)$ & \\
Other congenital & $57(13.38 \%)$ & $9(23.07 \%)$ & \\
$\quad$ anomalies & & & \\
Respiratory & $48(14.41 \%)$ & $19(14.39 \%)$ & \\
Musculoskeletal & $52(15.61 \%)$ & $15(11.36 \%)$ & \\
CNS & $9(2.7 \%)$ & $11(8.33 \%)$ & \\
Urinary & $7(1.64 \%)$ & $2(5.12 \%)$ & \\
Chromosomal & $8(1.87 \%)$ & $1(2.56 \%)$ & \\
\hline
\end{tabular}

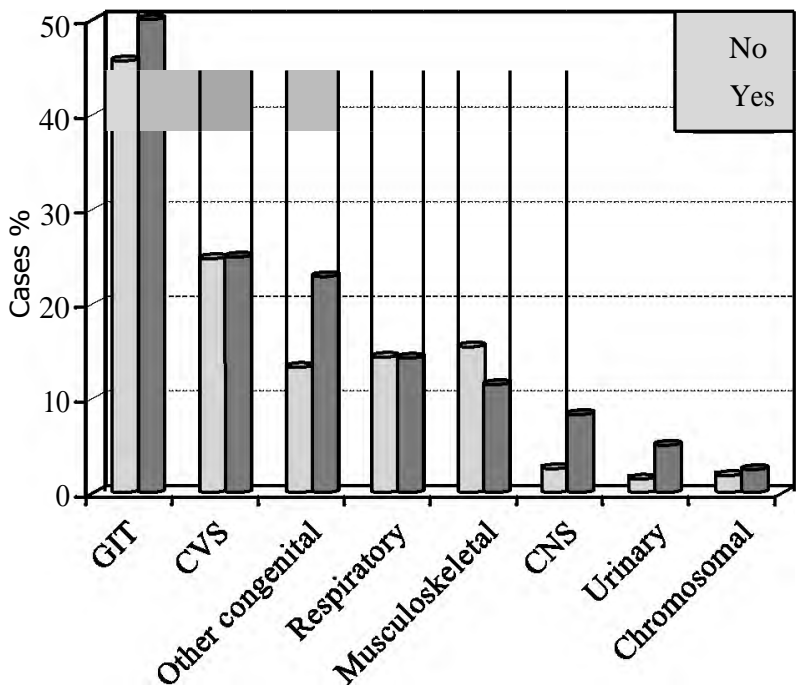

Fig. (5): Relation between congenital anomalies and consanguinity.

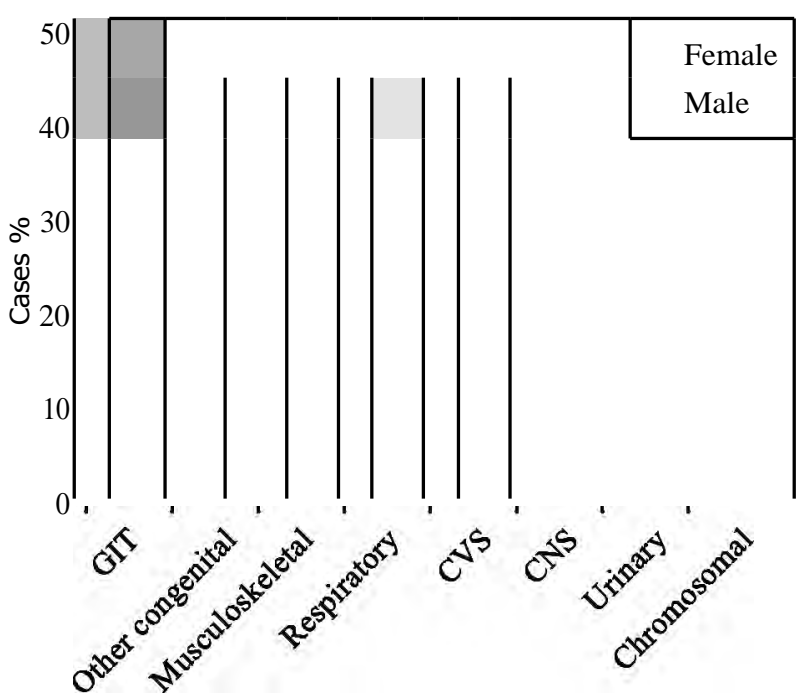

Fig. (6): Shows relation between congenital anomalies and sex distribution in study group with high percentage of anomalies in male group with significance difference $(p<0.05)$.

\section{Discussion}

Congenital anomalies have been known and recognized for centuries. Congenital anomalies comprise a wide range of abnormalities of body structure or function that are present at birth and are of prenatal origin. It is a stimulating problem for research because of the high frequency of their occurrence and the devastating effect they may have on the individual and his or her family [4] .

The rapid decline in the infant mortality and morbidity in the developed countries has focused the attention of pediatricians on the problem of congenital malformations. In the past the causes of the infant mortality used to be traced mostly in the prevalence of infectious diseases [5] 
Any substance that causes birth defects is known as a teratogen. Some disorders can be detected before birth through prenatal diagnosis.

Birth defects may be the result of genetic or environmental factors. This includes errors of morphogenesis, infection, epigenetic modifications on a parental germ line, or a chromosomal abnormality. The outcome of the disorder will depend on complex interactions between the pre-natal deficit and the post-natal environment [6]

In our study we reviewed case notes of Neonatal Intensive Care Units for neonates admitted from January 2014 to January 2015 and we found 465 $(42.08 \%)$ neonates with variable degree of congenital anomalies with mean age $(36.45 \pm 2.61)$ weeks, where Post term represented $2(0.4 \%)$, Full term 336 (72.3\%), Preterm 127 (27.3\%). The mean weight was $2.743 \pm 1.79 \mathrm{Kg}$. This low birth weight was mostly associated with preterm labor and intra uterine growth retardation.

Hayelom et al., [7] reported that the perinatal morbidity and mortality are more frequent in LBW than in normal infants and has become the second cause of death in this period, after premature birth. Rasmussen and Associates [8] reported a high frequency of birth defects among premature infants and/or those of low birth weight.

Madi et al., [9] showed that a suboptimal weight at birth may impair neurological function and can cause chronic disease, such as hypertension in the perinatal period, during infancy, and even in adult hood.

Other studies done by Pendray, [10] showed higher incidence among full term with appropriate gestational age infants.

The difference in distribution of congenital anomalies between term and preterm infants may have several explanations. For term infants, the congenital anomaly is likely the primary reason for admission, whereas prematurity may be the primary reason for preterm infants. More severe congenital anomalies may not be compatible with life in the preterm infant. In addition, term infants with surgically correctable congenital anomalies may be admitted to surgical neonatal intensive care unit [11].

Increase percentage of congenital anomalies $(42.08 \%)$ in our study mostly related to that we are tertiary referral center and we include neonatal surgical unit in our study this in agreement with Demirhan et al., [12] who recorded that presence of surgical neonatal unit cases as part of the study group increased the number of congenital anomaly cases as most of the surgical problems in the neonatal period are congenital in nature.

Behrman, [13] reported that the prevalence of congenital abnormalities depending on the place and population. It is evident that the prevalence and type of congenital malformations differ from one country to another. Even in the same country it differs from one locality toanother.

According to demographic factors, in our study Giza showed highest percentage of congenital anomalies (34.83\%), followed by Cairo (30.32\%), Lower Egypt (21.58\%), Delta (5.80\%) Upper Egypt (2.58\%), Canal (1.29\%).

The rate of malformations in male $307(66.0 \%)$ in our study is nearly twice that of females 158 $(34.0 \%)$ with statistically significant association between congenital anomalies and sex with $p$-value $<0.03$ in male preponderance in GIT anomalies $153(49.83 \%)$, followed by musculoskeletal system 48 (15.68\%), Respiratory system 38 (12.41\%), Cardiovascular system anomalies 25 (8.14\%).

This result is the same as that observed by Colalipour et al., [14] in Iran. This in agreementwith the Egyptian study by Shawky et al., [15] with male to female ratio $1.8: 1$.

EUROCAT et al., [16] Showed that higher incidence in Male with congenital anomalies than females, may be because of the fact that the females were afflicted with more lethal congenital malformations and could not survive to be born with signs of life.

Tarin et al., [17] reported that many studies have found that the frequency of occurrence of certain congenital malformations depends on the sex of the child. For example, pyloric stenosis occurs more often in males while congenital hip dislocation is four to five times more likely to occur in females.

While, the study of Waqas Jehangir et al., [18] showed that there is not significant role between gender of the babies and the development of congenital anomalies.

In our study mean maternal age was $27.43 \pm 4.79$. This agree with the study done by Grag et al., [19] which showed that the mean maternal age (in years) of those with congenital abnormality is $29 \pm 5$, also noted that a high occurrence of congenital abnormality among women who are between 33 and 39 years of age. 
Anjum et al., [20] showed that higher incidence of malformations in babies born to mothers aged less than 20 years or in babies born to mothers aged over 35 years.

About mode of delivery, it was $(66.45 \%)$ of patients in our study delivered with C.S while $(35.48 \%)$ delivered vaginally. This agree with Malay et al., [21] how reported significant higher frequency of congenital anomalies in neonates delivered by CS than control population (54.4\% versus $29.7 \%$ ).

Ostovar et al., [22] have found that cesarean section rates have gone up for all groups of birthing women, regardless of age, the number of babies they are having, the extent of health problems, their race/ethnicity, or other characteristics.

While Shawky et al., [15] demonstrated no association between the frequency of congenital anomalies and the route of delivery.

In our study (10.32\%) of mothers have chronic illness with $1.07 \%$ have anemia, $(2.58 \%)$ have cardiac disease, $(2.58 \%)$ have D.M, also (5.16\%) have hypertension and $(1.93 \%)$ with other diseases.

This agrees with the study of Ordonez et al., [23] which demonstrated that several maternal diseases, such as diabetes mellitus or high blood pressure, are associated with a higher risk for fetal or neonatal problems. Offspring of diabetic mothers had 8.95 times more probabilities of having a major malformation and 4.95 times more probabilities of having a minor defect. Offspring of mothers with diabetes mellitus, bronchial asthma, hypertension or hypothyroidism have a higher risk of presenting a congenital malformation, when compared with offspring of healthy mothers.

In our study the presence of perinatal complications represents $(16.12 \%)$ with Pre mature rupture of membrane $(5.16 \%)$ this percentage of pre mature rupture of membrane may be related to cervical insuffency, Nutritional deficits, low socioeconomic status, or there was episodes of bleeding any time during pregnancy in cases we reviewed in our study while Smith et al., [24] reported that (2.3\%) of cases with PROM and demonstrated that the increased neonatal morbidity associated with PROM appears to be inversely related to gestational ageincreased risk of chorioamnionitis is related to increased time from PROM to delivery.

Oligohydraminosin our study (1.72\%) Shawky et al., [15] Showed that no significant association between the frequency of congenital anomalies and presence of oligohydramnios. While the study done by Yasser et al., [25] reported that congenital anomalies were significantly associated with the presence of maternal oligohydramnios compared with controls ( $14.6 \%$ versus $8 \%, p<0.05)$.

Blackburn, [26] reported that the constraints on fetal movement imposed by oligohydramnios can result in a cascade of developmental events resulting in fetal anomalies like congenital contractures (due to relative or incomplete immobilization of the joints in a confined space); lung hypoplasia (lack of room for development of the thorax and distension of lung tissue); dysmorphicfacies including micrognathia, low set ears, small alaenasi and hypertelorism (molding of the face by compressive forces); growth restriction (fetal motor activity is important for normal development of muscle mass and weight gain); perhaps microgastria (lack of stretching and distension because the volume of amniotic fluid available for swallowing is reduced) and also severe fetal renal anomalies (agenesis, dysplasia or obstructive disorder) may lead to oligohydramnios because of decreased or no urine output.

In our study multiple pregnancies (twin or triple) represented $(2.15 \%)$.

Wojdyla et al., [27] reported that Major and minor malformations are more common in twins than in singletons, with monozygotic twins more commonly affected than dizygotic twins

Polyhydraminosin our study was (1.93\%) Villar et al., [28] reported that $55 \%$ of cases with polyhydramnios $(10.8 \%)$ had more than one malformation, $13.4 \%$ of them had a chromosomal aberration and $32 \%$ had multiple malformations that do not constitute a syndrome.

Pre-eclampsia in our study was $(3.44 \%)$. Ananth et al., [29] found a higher frequency of Congenital malformations in the off spring of mothers having pre-eclampsia $(39.43 \%)$ compared to controls (1.64\%) and demonstrated thatchromosomal abnormalities and structural chromosomal abnormalities are considered pregnancy associated risk factors for preeclampsia.

With regard to pattern of congenital anomalies in our study, the most common system involved was GIT $(48.60 \%)$ with high percentage in intestinal obstruction (31.41\%), imperforate anus (10.75\%), tracheoosophogeal fistula (10.75\%), CHPS (7.96\%), followed by cardiovascular $(24.30 \%)$, respiratory system $(14.62 \%)$, musculoskeletal system (14.19), CNS (4.30\%), and with low percent- 
age in urinary tract system (1.93\%) and chromosomal abnormalities $(1.93 \%)$. This is in agreement with Suguna Bai et al., [30] who reported that GIT anomalies $(33.3 \%)$ with high percentage in TOF followed by imperforate anus.

On the other hand Adhia et al., [31] showed that the most common system involved was musculoskeletal system (33.2\%) followed by gastrointestinal tract (GIT) (15\%), CNS (11.2\%), genitourinary $(10.5 \%)$, and cardiovascular system $(9.1 \%)$.

Other study by Khatemi et al., [32] recorded that higher incidence of CNS (30.2\%) malformations followed by GIT (15.2\%) and musculoskeletal system $(10.4 \%)$.

These variations between different studies could be explained by the effect of different racial, ethnic and social factors in various parts of the world or different geographical, nutritional and socioeconomic factors. Other explanations for these variations in birth defect incidence are the criteria of diagnosis; Gololpour et al., [14] Gastrointestinal malformation was found to be the most common single system abnormality detected by Sawardekar, [33] although in his study orofacial clefts (cleft lip and/or palate) were included in the GIT malformations. In the same study the author attributed the lower incidence rate of CVS anomalies to the fact that 24-hour in-houseechocardiography was not available in his hospital.

Incidence of consanguinity in our study was $(28.81 \%)$ with higher incidence of 1 st degree consanguinity $(53.7 \%)$ and $(35.1 \%)$ in 2 nd degree, $(7.5 \%)$ in 3 rd degree and $(3.7 \%)$ in 4 th degree.

In our study, there is statistically significant association between Congenital anomalies and consanguinity with $p$-value $<0.001$ with high incidence in GIT anomalies (50.0\%), followed by Cardiovascular anomalies $(25.0 \%)$ respiratory system (14.39\%) and musculoskeletal system (11.36\%).

Sefiani et al., [34] reported that consanguinity rate among Arab population specifically first cousin marriages may reach $25-30 \%$ of all marriages and demonstrated that most of the genetic syndromes were due to autosomal recessive inheritance and this isdue to high degree of consanguinity.

In our study there is statistically significant association between drugs taken by the mother during pregnancy and type of congenital anomalies with $p$-value $<0.02 .39(8.38 \%)$ of mothers taking drug during pregnancy, with $(43.58 \%)$ of them took Aldomet, $(20.51 \%)$ antibiotcs, $(15.38 \%)$ Asprin, Heparin, Clexcane, $(10.25 \%)$ took Tonics and (7.69\%) took other drugs.

With high incidence shown in GIT anomalies (51.28\%), followed by cardiovascular system anomalies $(28.20 \%)$, respiratory system $(15.38 \%)$, musculoskeletal system anomalies (10.25\%).

This agree with the results from Royal College of Obstetriciansand Gynecologists, 2011 which reported that an infant born with esophageal atresia with fistula, congenital heart disease, absent left kidney and hypospadias was exposed to methyldopa "Aldomet" throughout pregnancy and clomiphene (in the $1{ }^{\mathrm{st}}$ trimester). Jennifer et al., [35] also reported that characteristic skeletal abnormalities associated with warfarin ingestion during pregnancy.

Waller et al., [36] reported thatabout 2-3\% of all birth defectsresult from the use of drugs other than alcohol. Drugs taken by pregnant women can affect the fetus by acting directly on it, causing damage, abnormal development (leading to birth defects) or death. They can alter the function of the placenta by constricting blood vessels thus reducing the supply of oxygen and nutrients to the fetus from the mother. The result is under weight, under developed and may be abnormal developed baby.

Shawky et al., [15] in an Egyptian study reported that $27.5 \%$ of mothers received folic acid or multivitamin which is significantly lower than that in the control group. Methylenetetrahydrfolatereductase (MTHFR) genetic polymorphism (1298A/C) is considered a risk factor in Egyptian mothers with Down syndrome, also demonstrated thatmedium serumfolate concentrations among nonpregnant women of childbearing age was reported to be decreased $16 \%$ and $\mathrm{RBC}$ folateconcentration decreased $8 \%$, and it is recommended that all women of childbearing age who are capable of becoming pregnant should consume $400 \mu \mathrm{g}$ of folic acid daily to reduce the occurrence of neural tube defects in affected pregnancy.

Beil et al., [37] reported that folic acid supplementation for 1 year before conception might significantly reduce the risk for preterm delivery, according to an analysis involving more than 38,000 women.

In our study (30.53\%) showed mortality from congenital anomalies. Shawky et al., [15] reported that in Egypt, infant mortality rate due to birth defects is about $15 \%$ of all infant deaths (22/1000). 
This in agreement with the study of Grover et al., [38] which reported that congenital abnormality plays a major role in morbidity and mortality of neonates.

Birch et al., [39] also showed that congenital anomalies are an important cause of neonatal mortality both in developed and developing countries and it accounts for $8-15 \%$ of perinatal deaths and $13-16 \%$ of neonatal deaths.

In conclusion: Incidence of major congenital anomalies among admitted cases was high as the neonatal units included a surgical unit. Consanguinity still was high among cases with congenital anomalies in spite of awareness of the community.

Mortality rate was high. This is attributed to the critical condition of surgical congenital anomalies of our cases. Maternal drug intake and diabetes in pregnancy was among factors contributing to increased incidence of congenital anomalies in our study.

\section{References}

1- HUDGINS L. and CASSIDY S.B.: Congenital anomalies. In Martin R.J., Fanroff A.A., Walsh M.C. (eds). NeonatalPerinatal Medicine. 8 th (edn), Philadelphia, MosbyElsivier, pp 561-81, 2006. Journal of Surgery Pakistan (International), 18 (1) January- March 2013.

2- TOMATIR A.G., DEMIRAN H., SORKUN H.C., KOKSAL A., OZERDEM F. and GLENGIR N.: Major congenital anomalies: A five year retrospective regional study in Turkey. J. Genet Mol. Res., 8: 19-27, 2009.

3- EKEWRE O.E., McNEIL R., AGIM B., JEMINIWA B., ONI O. and PAM S.: A retrospective study of congenital anomalies presented at tertiaryhealth facilities in Jos, Nigeria. JPCS, 3: 24-8, 2011.

4- JEHANGIR W., ALI F., JAHANGIR T. and MASOOD M.S.: Prevalence of gross congenital malformations at birth in the neonates in a tertiary care hospital. APMC, 3: 47-50, 2009.

5- STOLL B.J.: Congenital anomalies. In Kliegman R.M., Jenson H.B., Behrman R.E., Stanton B.F. (eds) Nelson Textbook of pediatrics 18 th (edn) Philadelphia WB Saunders, pp. 711-3, 2008.

6- GREGORY W. RUTECKI: "Pre-Prenatal Care: A Primary Care Primer on the Future". Consultant Live. Com . Retrieved 25 September 2010.

7- HAYELOM K. MEKONEN, BALKACHEW NIGATU and WOUTER H. LAMERS: Birth weight by gestational age and congenital malformations in Northern Ethiopia. BMC Pregnancy and Childbirth (2015) 15: 76 Received: 11 February 2014 Accepted: 19 March 2015.

8- RASMUSSEN S.A., FLORES A., KIRBY R.S., EDOMDS L.D. and WILLAMS L.J.: Decline in the prevalence of spina bifida, anencephaly by race/ethnicity: 1995-2002. Pediatrics, 116 (3): 580-586, 2005.
9- MADI S.A., AL-NAGGAR R.L., AL-AWADI S.A. and BASTAKY L.A.: Profile of major congenital malformations in neonates in Al-Jahra Region of Kuwait. East Mediterr Health J., 11 (4): 700-6, 2005.

10- PENDRAY M., JONES H. and BERRY M.: Infants with congenital anomalies admitted to neonatal intensive care units. Am. J. Perinatol., 21 (4): 199-206, 2004.

11- SYNNES A.R., BUCHANAN L., RUTH C. and ALBERSHEIM S.: Management of the newborn delivered at the threshold of viability. BCMJ, Nov. 50 (9): 498-508, 2008.

12- DEMIRHAN O., TÜRKMEN S., SCHWABE G.C., SOYUPAK S., AKGÜL E., TASTEMIR D., KARAHAN D., MUNDLOS S. and LEHMANN K.: Ahomozygous BMPR1B mutation causes a new subtype of acromesomelicchondrodysplasia with genital anomalies. Journal of Medical Genetics, 42: 314-317, 2005. (doi: 10. 1136/jmg. 2004. 023564). Journal of Molecular Endocrinology, 45: 257-279, 2010.

13- BEHRMAN R.E.: The field of paediatrics. In Nelson Textbook of Paediatrics. 14 th edition. WB Sanders Co, Philedephia; 1992: 1-5 BMC Research Notes, 5: 177 doi: 10. 1186/1756-0500-5-177, 2012.

14- GOLALIPOUR M.J., AHMADPOUR M. and VAKILI, M.A.: Congenital malformations at a referral hospital in Gorgan, Islamic Republic of Iran. Easren Mediterranean Health Journal, 11 (4): 707-715, 2005.

15- SHAWKY R.M. and SADIK D.I.: Congenital malformations prevalent among Egyptian children and associated risk factors. Egyptian Journal of Medical Human Genetics, 12: 69-78, 2011.

16- EUROCAT: A review of environmental risk factors for congenital anomalies. Newtownabbey, Northern Ireland: E. S. O. C. A. EUROCAT, EUROCAT, European surveillance of congenital anomalies, University of Ulster, 2008.

17- TaRIN J.J., GARCIA-PEREZ M.A., HERMENEGILDO C. and CANO A.: Changes in sex ratio from fertilization to birth in assisted-reproductive-treatment cycles. ReprodBiol. Endocrinol. RB\&E, 12: 56, 2014.

18- WAQAS JEHANGIR, FAROOQ ALI, TAIMOOR JAHANGIR and MUHAMMAD SAJJAD MASOOD: Prevalence of Gross Congenital Malformations at birth in the Neonates in a Tertiary Care Hospital. A. P. M. C, Vol. 3 No. 1 January-June 2009.

19- GRAG A., CANOLLY C. and HOLLIER L.M.: Maternal age and malformations in singleton births. J. Obstet. Gynecol., 96: 701-6, 2000. Publisher Full Text BMC Research Notes, 5: 177 doi: 10. 1186/1756-0500-5-177, 2012.

20- ANJUM R., SAHER S. and SOOMRO N.: Frequency of congenital anomalies and associated maternal risk factors. Pak. J. Surg., 22: 18-23, 2006.

21- MALAY KUMAR DASGUPTA, SHATANIK SARKAR, CHAITALIPATRA, KAUSTAV NAYEK and PRASANTA RAY KARMAKAR: Prevalence of Congenital Anomalies in Neonates and Associated Risk Factors in a Tertiary Care Hospital in Eastern India J. Clin. Neonatol., Jul-Sep. 2 (3): 131-134. doi: 10. 4103/2249-4847. 119998, 2013.

22- OSTOVAR R., RASHIDIAN A., POURREZA A., HOSSEIN RASHIDI B., HANTOOSHZADEH S., 
EFTEKHAR ARDEBILI H. and MAHMOUDI M. Cesarean Section Ram Study Themembers of the panel: Developing criteria for Cesarean Section using the RAND appropriateness method. BMC Pregnancy and Childbirth, 10 (1): 52, 2010

23- ORDÓN 'EZ M.P., NAZER J., AGUILA A. and CIFUENTES L.: (Congenital malformations and chronic diseases of the mother. Latin American Collaborative Study of Congenital Malformations (ECLAMC)19711999) Rev Med Chil., 131: 404-11, 2003. Indian J. Hum. Genet., Sep-Dec. 16 (3): 159-163. doi: 10. 4103/09716866. 73412, 2010.

24- SHAW-SMITH C.: (July 2006). "Oesophageal atresia, tracheo-oesophageal fistula, and the VACTERL association: Review of genetics and epidemiology". Journal of medical genetics 43 (7): 54554. doi: 10. 1136/jmg. 2005. 038158. PMID 16299066. 302" Series 1 - The Boy Whose Skin Fell Off". Channel 4. Retrieved 2009-02-28, 2004.

25- YASIR A. MOHAMMED, RABAH M. SHAWKY, AMAL A.S. SOLIMAN \& MAHER M. AHMED: Chromosomal study in newborn infants with congenital anomalies in Assiut University Hospital. doi: 10. 1016/j. ejmhg. 02. 003, 2011.

26- BLACKBURN S.T.: Reproductive and developmental process. Maternal, fetal and neonatal physiology: A clinical perspective textbook, 3 rd ed. Elsevier Health Sciences Edition, p. 107-15, 2007.

27- WOJDYLA D., ABALOS E., GIORDANO P., FAMOT U., BERGSJ P., BAKKETEIG L., LUMBIGANON P., VILLAR J., CARROLI G., CAMPODORICO L., ALMAZRON Y., LINDHEIMER M. and KRAMER M.: Preeclampsia gestational hypertension and intrauterine growth restriction, related or independent conditions. Am. J. Obstet. Gynecol., 194 (4): 921-31, 2006.

28- VILLAR J., CARROLI G., WOJDYLA D., ABALOS E., GIORDANO P., BA' AQUEEL L., FAMOT U., BERGSJ P., BAKKETEIG L., LUMBIGANON P., CAMPODORICO L., AL-MAZRON Y., LINDHEIMER M. and KRAMER M.: Preeclampsia gestational hypertension andintrauterine growth restriction, related or independent conditions. Am. J. Obstet. Gynecol., 194 (4): 921-31, 2006.
29- ANANTH C.V. and SAVITZ D.A.: Vaginal bleeding and adverse reproductiveoutcome: A meta-analysis. Pediatr Perinat Epidemiol., 8 (1): 62-8, 2008

30- SUGUNA BAI N.S., HUDGINS L. and CASSIDY S.B.: Congenital anomalies. In: Martin RJ, Fanaroff A.A., Walsh MC, editors. Neonatal-Perinatal Medicine. ${ }^{8}$ ed. Philadelphia: Mosby-Elsevier, pp. 561-81, 2006.

31- ADHIA R.A. and PATEL Z.M.: Birth defects surveillance study. Indian J. Pediatr., 72: 489-91, 2005.

32- KHATEMI F. and MAMOORI G.A.: Survey of congenital major malformations in 10/000 newborns. Iran J. Pediatr., 15: 315-20, 2005 .

33- SAWARDEKAR K.P.: Profile of major congenital malformations at Nizwa Hospital, Oman: 10 year review. J. Paediatr. Child Health, 41: 323-330, 2005.

34- SEFIANI A., JAOUAD I.C., ELALAOUI S.C., SBITI A. and ELKERHBELMAHI L.: Consanguineous marriages in Morocco and the consequence for the incidence of autosomal recessive disorders. J. Biosoc. Sci., 41 (5): 575-81, 2009

35- JENNIFER J. KURINCZUK, JENNIFER HOLLOWELL, PATRICIA A. BOYD, LAURA OAKLEY, PETER BROCKLEHURST and RON GRAY: Inequalities in infant mortality project briefing paper 4 . The contribution of congenital anomalies to infant mortality. Oxford: National Perinatal Epidemiology Unit, 2010.

36- WALLER D.K., SHAW G.M., RASMUSSEN S.A., et al.: Prepregnancy obesity as a risk factor for structural birth defects. Arch. Pediatr. Adolesc. Med., 161: 745-750, 2007.

37- BEIL L.: Medscape Medical news. http: //www. medscape. $\mathrm{com} /$ viewarticle/569590?sssdmh $=\mathrm{dm} 1.334737 \& \mathrm{src}=$ nldne; Jan 31, 2008.

38- GROVER N.: Congenital malformations in Shimla. India J. Paediatr., 67: 249-51, 2000. BMCResearch Notes, 5: 177 doi: 10. 1186/1756-0500-5-177, 2012.

39- BIRCH M.R., GRAYSON N. and SULLIVAN E.A.: AIHW Cat. No. PER 23. Birth Anomalies Series No. 1. Sydney: AIHW National Perinatal Statistics Unit. Recommendations for development of a new Australian birth anomalies system: A review of the congenital malformations and birth defects data collection, 2004. 


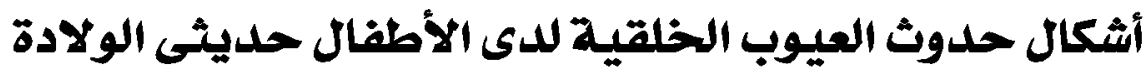

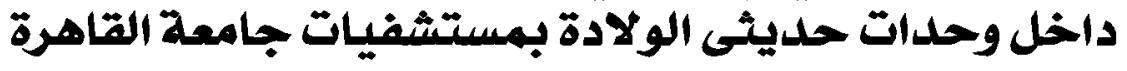

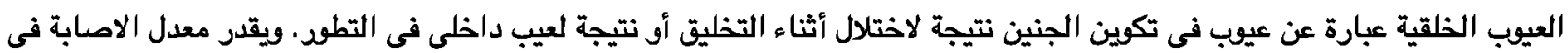

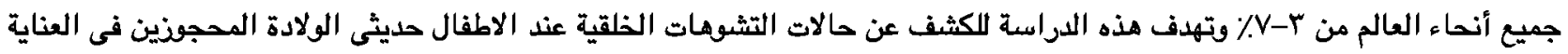

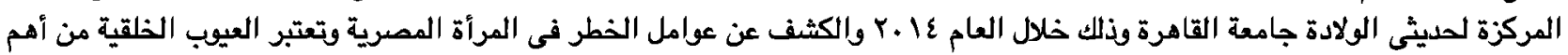
أسباب الوفيات سواء في الدول المتقدمة أو الدول النقادة النا مية.

وقد تم فى هذه الريسالة فحص سجلات المرضى بأثّر رجعى البحث عن وجود تثوهات وعيوب خلقية في الاطفال فى وحدة الرعاية المركزة

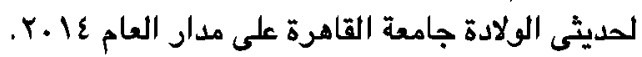

وقد توصل البحث لهذه النتائج: لقد تم فحص ه ـ 11 من سجلات الاطفال الذين تم حجزهم فى وحدة الرعاية المركزة لصديثى الولادة لمدة

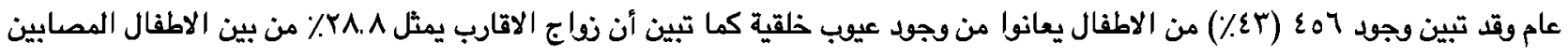
بالعيوب الخلقية.

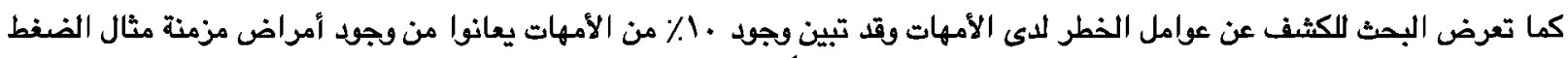

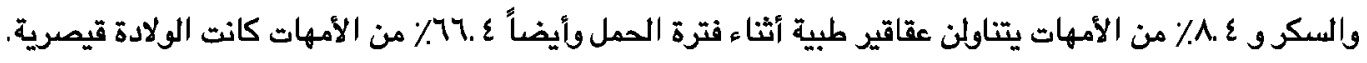

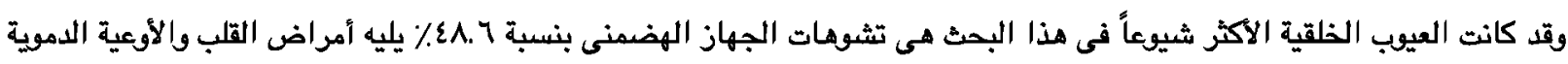

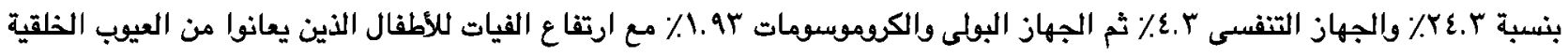

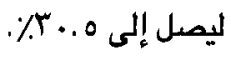

الهلخص: العيوب الخلقية قد تؤدى إلى العجز على المدى الطويل والتى قد يكن لها تأثيرات ضخمة على الأفراد والأسمر ونظم الرعاية الصحية والمجتمعات.

وقد توصلت نتائج البحث إلى أن نسبة زواج الأ قارب مرتفعة فى الصالات التى تعانى من العيوب الخلقية وذلك يرجع لأنتا مركز الاحالة

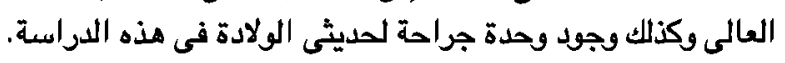

أيضاً توصل البحث إلى أن وجود بعض العيوب الخلقية ممكن تجنبها عن طريق أخذ التطعيمات وبتاول حمض الفوليك واليود والمتابعة

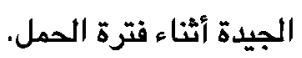

